Pacific Journal of Mathematics

BEST POSSIBLE RESULTS IN A CLASS OF INEQUALITIES 


\title{
BEST POSSIBLE RESULTS IN A CLASS OF INEQUALITIES
}

\author{
P. D. Johnson, JR. AND R. N. Mohapatra
}

In this paper we shall prove the following theorem.

Theorem. Suppose $1<p \leqq \infty$, and $r p>1$ if $p<\infty$, $r>0$ if $p=\infty$. Suppose the matrix $A=\left(a_{n k}\right)$ with $a_{n k}=n^{-r}$ $(k \leqq n), \quad a_{n k}=0 \quad(k>n)$. Suppose $\tilde{w}$ be the subset of $w$ consisting of nonnegative, monotone sequences. Then $\left\{n^{r-1}\right\}_{n}$ is maximum, with respect to $<$, in $I$ where

$$
I=\left\{b \in \tilde{w}: \text { for some } K>0,\|A \mid b x\|\left\|_{p} \leqq K\right\| x \|_{p}\right.
$$

for all $\left.x \in l_{p}\right\}$.

1. Let $w$ be the space of all real or complex sequences. For $x=\left\{x_{n}\right\} \in w, y=\left\{y_{n}\right\} \in w, x y$ is the sequence $\left\{x_{n} y_{n}\right\}$, and $|x|=$ $\left\{\left|x_{n}\right|\right\}$. Let $A=\left(a_{n k}\right)(n, k=1,2, \cdots)$ be a lower triangular matrix with nonnegative entries. $A x$, the $A$ transform of a sequence $x \in w$, is given by

$$
(A x)_{n}=\sum_{k=1}^{\infty} a_{n k} x_{k} .
$$

$\ell_{p}$ space will have its usual meaning and $\|\cdot\|_{p}$ will denote the usual norm, if $1 \leqq p \leqq \infty$, or quasinorm, if $0<p<1$.

Let $C=\left(c_{n k}\right)$ be the Cesàro matrix that is $c_{n k}=n^{-1}(k=1,2, \cdots, n)$ and $c_{n k}=0(k>n)$. Hardy [2, Theorem 215] proved the following inequality:

THEOREM A. If $p>1, x_{n} \geqq 0(n=1,2, \cdots)$, then

$$
\|C x\|_{p} \leqq\left(\frac{p}{p-1}\right)\|x\|_{p} \text {. }
$$

Subsequently Petersen [4] and Davies and Petersen [1] generalized Theorem $\mathrm{A}$ by replacing the Cesàro matrix $C$ by a lower triangular matrix $A$ satisfying certain conditions. Their results were of the form

$$
\|A x\|_{p} \leqq C(p)\|d x\|_{p}
$$

where $d=\left\{d_{n}\right\}$ is a suitable sequence and $C(p)$ is a positive constant which depends upon $p$.

In [3] we had tried to systematize and unify inequality results of the following form:

There exists $K>0$ such that for all $x \in \mu$, 


$$
\|A|b x|\|_{\lambda} \leqq K\|x\|_{\mu},
$$

where $\left(\lambda,\|\cdot\|_{\lambda}\right),\left(\mu,\|\cdot\|_{\mu}\right)$ are normal, normally quasinormed $F K$ spaces, $b$ is a sequence in $\lambda$, and $A$ is a lower triangular matrix with nonnegative entries.

In [3] we ordered the sequences in $w$ by defining that for $b, c \in w, b<c$ (b is less than $c)$ if and only if, for some $M>0$, $\left|b_{n}\right| \leqq M\left|c_{n}\right|$ for all $n$.

Now one can observe that an inequality of the form (2) is better the smaller the $K$, or the larger the sequence $b$ with the notion of largeness of sequences defined above.

It is useful to note that (see [3], Proposition 3.1) if a set $S$ of sequences is closed under addition, and has the property that $x \in S$ implies $|x| \in S$ (which is satisfied if every sequence in $S$ is nonnegative), then a sequence $b \in S$ is maximal in $S$ with respect to $<$ (meaning that $x \in S$ and $b<x$ imply that $x<b$ ) if and only if $b$ is maximum in $S$ (meaning $x<b$ for every $x \in S$ ).

In $[3$, remarks at the end of $\S 8]$ we have proved the following:

Theorem B. Suppose $1<p \leqq \infty$, and $r p>1$.

$$
\left.\sum_{n=1}^{\infty} \frac{1}{n^{r p}}\left|\sum_{k=1}^{n}\right| k^{r-1} x_{k}\right|^{p} \leqq K(r, p) \sum_{k=1}^{\infty}\left|x_{k}\right|^{p},
$$

where $K(r, p)$ is a positive constant which depends upon $r$ and $p$.

If we write $A=\left(a_{n k}\right)$ with $a_{n k}=n^{-r}(k=1, \cdots, n)$ and $a_{n k}=0$ $(k>n)$, and $\lambda=\mu=\ell_{p}$, then we find that Theorem $\mathrm{B}$ is a result of the form (2). It was shown in [3, Theorem 9.3] that the inequality (2) with $b=\left\{n^{r-1}\right\}$ is not best possible, and that, indeed, there is no best possible inequality (2) for this triple $A, \lambda, \mu$. (It is interesting to note that if $p=1, r>1$, the inequality (2) with $b=\left\{n^{r-1}\right\}$ holds and is best possible (by [3, Corollary 4.9]).) However, this result was a little unsatisfying because, in the special case $r=1$, the only sequences $b$ satisfying (2) and strictly greater than $e=\{1,1, \cdots\}$, which we could actually find were far from monotone. They were like $e$ with a subsequence tending to infinity thrown in, sparsely.

In [3, Problem 9.4], we had wondered if $\left\{n^{r-1}\right\}_{n}$ is maximal (equivalently, maximum) among the monotone nonnegative sequences satisfying (2). The object of this note is to show that the answer to this question is in fact in the affirmative. Thus, in particular, Hardy's inequality is the best in its class of inequalities.

We shall precisely prove the following:

THEOREM. Suppose $1<p \leqq \infty$, and $r p>1$ if $p<\infty, r>0$ if 
$p=\infty$. Suppose the matrix $A=\left(a_{n k}\right)$ with $a_{n k}=n^{-r}(k \leqq n), a_{n k}=0$ $(k>n)$. Suppose $\widetilde{w}$ be the subset of $w$ consisting of nonnegative, monotone sequences. Then $\left\{n^{r-1}\right\}_{n}$ is maximum, with respect to $<$, in I where

$$
I=\left\{b \in \widetilde{w}: \text { for some } K>0,\|A|b x|\|_{p} \leqq K\|x\|_{p}\right.
$$

for all $\left.x \in \ell_{p}\right\}$.

Proof. It has been mentioned earlier that $\left\{n^{r-1}\right\} \in I$ (see [3], §8). Suppose $b \in I$, and $b \nless\left\{n^{r-1}\right\}$. Then $\left\{n^{1-r} b_{n}\right\}_{n}$ is unbounded. We shall first show that

$$
\left\{n^{-r} \sum_{k=1}^{n} b_{k}\right\}_{n} \notin \ell \infty \cdots
$$

If $b$ is nonincreasing, then

$$
n^{-r} \sum_{k=1}^{n} b_{k} \geqq n^{1-r} b_{n},
$$

and if $b$ is nondecreasing, then

$$
(2 n)^{-r} \sum_{k=1}^{2 n} b_{k} \geqq(2 n)^{-r} \sum_{k=n}^{2 n} b_{k} \geqq 2^{-r} n^{1-r} b_{n},
$$

and we see the truth of (4).

Now, let

$$
x^{(m)}=\sum_{k=1}^{m} e_{k},
$$

where $e_{k}$ is the usual coordinate sequence with 1 at the $k$ th entry and zero elsewhere. The theorem will be proved if we only show that the sequence

$$
\left\{\left\|x^{(m)}\right\|_{p}^{-1}\left\|A \mid b x^{(m)}\right\| \|_{p}\right\}_{m}
$$

is unbounded.

Let $p=\infty$ we see that

$$
\left\|x^{(m)}\right\|_{p}^{-1}\left\|A \mid b x^{(m)}\right\|_{p} \geqq m^{-r} \sum_{k=1}^{m} b_{k} .
$$

The theorem follows by (4).

Let $p<\infty$. Then

$$
\begin{aligned}
\left\|x^{(m)}\right\|_{p}^{-1}\left\|A \mid b x^{(m)}\right\|_{p} & \geqq\left(m^{-1} \sum_{n=m}^{\infty} n^{-r p}\left(\sum_{k=1}^{m} b_{k}\right)^{p}\right)^{1 / p} \\
& =\left(m^{-1}\left(\sum_{k=1}^{m} b_{k}\right)^{p}\left(\sum_{n=m}^{\infty} n^{-r p}\right)\right)^{1 / p}
\end{aligned}
$$




$$
\begin{aligned}
& \geqq M\left[m^{-1}\left(\sum_{k=1}^{m} b_{k}\right)^{p} m^{1-r p}\right]^{1 / p} \\
& =M m^{-r} \sum_{k=1}^{m} b_{k}
\end{aligned}
$$

where $M$ is a positive constant independent of $m$. The proof is complete by appealing to (4).

\section{REFERENCES}

1. G. S. Davies and G. M. Petersen, On an inequality of Hardy's (II), Quart. J. Math., (Oxford) (2), 15 (1964), 35-40.

2. G. Hardy, J. E. Littlewood, and G. Polya, Inequalities, Cambridge University Press, 1934 .

3. P. D. Johnson and R. N. Mohapatra, Inequalities involving lower triangular matrices, Proc. London Math. Soc., (3), 41 (1980), 83-137.

4. G. M. Petersen, An inequality of Hardy's, Quart. J. Math., (Oxford) (2), 13 (1962), 237-240.

Received July 28, 1980.

AUBURN UNIVERSITY

AUBURN, AL 36849

AND

American University of Beirut

Beirut, Lebanon 


\title{
PACIFIC JOURNAL OF MATHEMATICS
}

\section{EDITORS}

\author{
DONALD BABBITT (Managing Editor) \\ University of California \\ Los Angeles, CA 90024 \\ Hugo Rossi \\ University of Utah \\ Salt Lake City, UT 84112 \\ C. C. MOORE and ARthur Agus \\ University of California \\ Berkeley, CA 94720
}

J. DUGUNDJI

Department of Mathematics

University of Southern California

Los Angeles, CA 90007

R. FINN and J. MILGRAM

Stanford University

Stanford, CA 94305

\section{ASSOCIATE EDITORS}
R. ARENS
E. F. BeCKENBACH
B. H. NeumanN
F. WoLF
K. YoSHIDA

\section{SUPPORTING INSTITUTIONS}

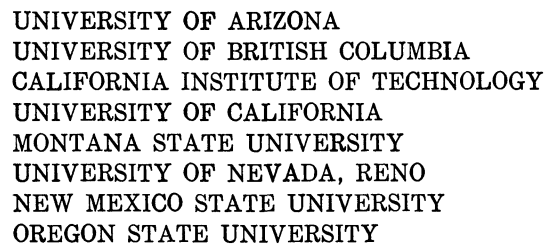

UNIVERSITY OF ARIZONA

UNIVERSITY OF BRITISH COLUMBIA

CALIFORNIA INSTITUTE OF TECHNOLOGY

UNIVERSITY OF CALIFORNIA

MONTANA STATE UNIVERSITY

UNIVERSITY OF NEVADA, RENO

NEW MEXICO STATE UNIVERSITY

OREGON STATE UNIVERSITY

\author{
UNIVERSITY OF OREGON \\ UNIVERSITY OF SOUTHERN CALIFORNIA \\ STANFORD UNIVERSITY \\ UNIVERSITY OF AAWAII \\ UNIVERSITY OF TOKYO \\ UNIVERSITY OF UTAH \\ WASHINGTON STATE UNIVERSITY \\ UNIVERSITY OF WASHINGTON
}

The Supporting Institutions listed above contribute to the cost of publication of this Journal, but they are not owners or publishers and have no responsibility for its content or policies,

Mathematical parers intended for publication in the Pacific Journal of Mathematics should be in typed form or offset-reproduced, (not dittoed), double spaced with large margins. Please do not use built up fractions in the text of the manuscript. However, you may use them in the displayed equations. Underline Greek letters in red, German in green, and script in blue. The first paragraph or two must be capable of being used separately as a synopsis of the entire paper. Please propose a heading for the odd unmbered pages of less than 35 characters. Manuscripts, in triplicate, may be sent to any one of the editors. Please classify according to the scheme of Math. Reviews, Index to Vol. 39. Supply name and address of author to whom proofs should be sent. All other communications should be addressed to the managing editor, or Elaine Barth, University of California, Los Angeles, California, 90024.

50 reprints to each author are provided free for each article, only if page charges have been substantially paid. Additional copies may be obtained at cost in multiples of 50 .

The Pacific Journal of Mathematics is issued monthly as of January 1966, Regular subscription rate: $\$ 114.00$ a year (6 Vol., 12 issues). Special rate: $\$ 57.00$ a year to individual members of supporting institution.

Subscriptions, orders for numbers issued in the last three calendar years, and changes of address shoud be sent to Pacific Journal of Mathematics, P.O. Box 969, Carmel Valley, CA 93924, U.S.A. Old back numbers obtainable from Kraus Periodicals Co., Route 100, Millwood, NY 10546.

PUBLISHED BY PACIFIC JOURNAL OF MATHEMATICS, A NON-PROFIT CORPORATION

Printed at Kokusai Bunken Insatsusha (International Academic Printing Co., Ltd.). 8-8, 3-chome, Takadanobaba, Shinjuku-ku, Tokyo 160, Japan. 


\section{Pacific Journal of Mathematics}

\section{Vol. 103, No. $2 \quad$ April, 1982}

Alberto Alesina and Leonede De Michele, A dichotomy for a class of positive

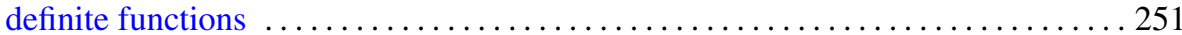

Kahtan Alzubaidy, Rank 2 -groups, $p>3$, and Chern classes . . . . . . . . . . 259

James Arney and Edward A. Bender, Random mappings with constraints on

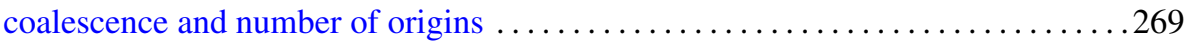

Bruce C. Berndt, An arithmetic Poisson formula . . . . . . . . . . . . . . . 295

Julius Rubin Blum and J. I. Reich, Pointwise ergodic theorems in 1.c.a. groups . . . 301

Jonathan Borwein, A note on $\varepsilon$-subgradients and maximal monotonicity . . . . . . . 307

Andrew Michael Brunner, Edward James Mayland, Jr. and Jonathan Simon,

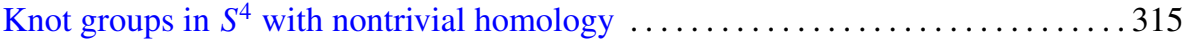

Luis A. Caffarelli, Avner Friedman and Alessandro Torelli, The two-obstacle

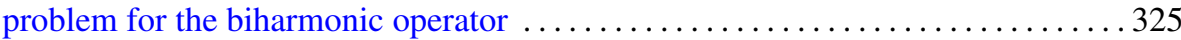

Aleksander Całka, On local isometries of finitely compact metric spaces . . . . . . 337

William S. Cohn, Carleson measures for functions orthogonal to invariant

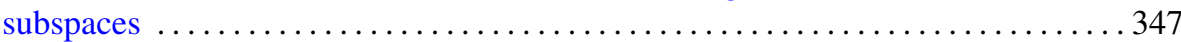

Roger Fenn and Denis Karmen Sjerve, Duality and cohomology for one-relator

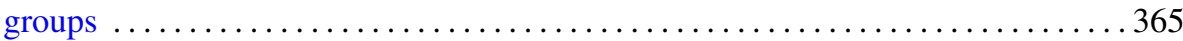

Gen Hua Shi, On the least number of fixed points for infinite complexes . . . . . . . 377

George Golightly, Shadow and inverse-shadow inner products for a class of linear

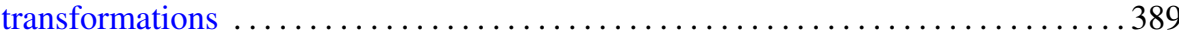

Joachim Georg Hartung, An extension of Sion's minimax theorem with an

application to a method for constrained games $\ldots \ldots \ldots \ldots \ldots \ldots \ldots \ldots \ldots \ldots . \ldots 4$

Vikram Jha and Michael Joseph Kallaher, On the Lorimer-Rahilly and

Johnson-Walker translation planes

Kenneth Richard Johnson, Unitary analogs of generalized Ramanujan sums .

Peter Dexter Johnson, Jr. and R. N. Mohapatra, Best possible results in a class of inequalities

Dieter Jungnickel and Sharad S. Sane, On extensions of nets

Johan Henricus Bernardus Kemperman and Morris Skibinsky, On the

characterization of an interesting property of the arcsin distribution ...

Karl Andrew Kosler, On hereditary rings and Noetherian $V$-rings

William A. Lampe, Congruence lattices of algebras of fixed similarity type. II . . . . 475

M. N. Mishra, N. N. Nayak and Swadeenananda Pattanayak, Strong result for real zeros of random polynomials

Sidney Allen Morris and Peter Robert Nickolas, Locally invariant topologies on free groups

Richard Cole Penney, A Fourier transform theorem on nilmanifolds and nil-theta functions

Andrei Shkalikov, Estimates of meromorphic functions and summability theorems

László Székelyhidi, Note on exponential polynomials

William Thomas Watkins, Homeomorphic classification of certain inverse limit spaces with open bonding maps $\ldots \ldots \ldots \ldots \ldots \ldots \ldots \ldots$

David G. Wright, Countable decompositions of $E^{n}$

Takayuki Kawada, Correction to: "Sample functions of Pólya processes" .

Z. A. Chanturia, Errata: "On the absolute convergence of Fourier series of the 